\title{
Numerical analysis of a testing technique to investigate the dynamic crack propagation in armour ceramic
}

\author{
Yannick Duplan ${ }^{1}$, Pascal Forquin ${ }^{1, *}$, Bratislav Lukić ${ }^{1}$, and Dominique Saletti ${ }^{1}$ \\ ${ }^{1}$ Univ. Grenoble Alpes, CNRS, Grenoble INP, 3SR laboratory, 38100 Grenoble, France
}

\begin{abstract}
Ceramic materials are numerically studied to understand their fracturing behaviour upon dynamic conditions and impact loadings. During a ballistic impact of a projectile against a ceramic armour system, an intense fragmentation composed of numerous oriented cracks, develops in the target. It is the reason why the conditions of crack initiation, propagation and arrest in these materials need to be investigated. In the present work, a dynamic testing configuration has been developed in order to characterise the dynamic fracture toughness $\left(K_{I, d}\right)$, considering a single crack that propagates from the specimen notch tip. The "Rockspall" testing technique, which employs a two-notch specimen loaded in a spalling experiment, was used. Thanks to the reflection of a compression wave into a tensile load from the sample free-end, a single dynamic crack is triggered. The sample geometry is optimised by means of a series of FE numerical simulations involving an anisotropic damage model.
\end{abstract}

\section{Introduction}

Dynamic crack propagation in brittle materials is present in many situation, such as protective structures subjected to impact loading, blasting of rocks or concrete, fragmentation in mining, or other military applications [1-3]. In these situations, the crack velocity is an important parameter that governs the damage and fracturing of the loaded structure or the impacted target. For several decades the dynamic crack propagation in brittle materials has been investigated. According to several authors, the limiting velocity of a crack is linked to the fracture toughness in mode I-opening according to the following equation [4]:

$$
\frac{K_{I}(v, t)}{K_{I}(0, t)} \cong \frac{1-v / C_{R}}{1-0.5 v / C_{R}}
$$

Thus, the fracture toughness in mode I-Opening at velocity $v\left(K_{I}(v, t)\right)$ decreases when the crack velocity tends to the Rayleigh wave speed $C_{R}[1,4]$. The surface (Rayleigh) wave speed can be calculated according to [1]:

$$
C_{R}=\frac{0.862+1.14 v}{1+v} C_{s}
$$

where $C_{s}=\sqrt{\mu / \rho}=\sqrt{E / 2(1+v) \rho}$ is the shear wave speed related to $\mu$ the shear modulus and $\rho$ the density.

Based upon the concept of conservation of energy, it was demonstrated that when the crack length becomes significantly larger than the initial crack size, the cracking velocity would tend to a limit close to $0.38 \mathrm{C}_{0}$ [5] where $\mathrm{C}_{0}$ is the $1 \mathrm{D}$ longitudinal wave speed given by $\sqrt{E / \rho}$.
Experimental studies later specified that in brittle materials, this velocity ranges from 0.40 to $0.60 C_{R}$ (around $0.5 C_{R}$ in glass and ceramic [6], $0.60 C_{R}$ in Plexiglass (brittle thermoplastic) and $0.40 C_{R}$ in Homalite-100 [7].

The determination of the critical dynamic fracture toughness $K_{c, d}$ is not as straightforward as its quasi-static homologue $K_{c}$. Indeed, if the tested structure or sample is loaded in an unbalance state, inertial effects acting on the sample makes the classical static relation between the stress-intensity factor $K_{I}$ and the crack length $a$ not applicable in dynamic situations. The measure of the stress field around the crack tip cannot be directly deduced from the applied load. Consequently, many studies had led to different results of dynamic fracture toughness. Some experimental studies have shown that, thanks to fields of displacement data obtained from digital image correlation (DIC), these methods can provide better predictions than strain gauges or external force cell [8].

The present paper aims to determine the optimised experimental configurations for crack velocity from the notch tip in a $\mathrm{SiC}$ material, and to determine its dynamic fracture toughness.

\section{Rockspall testing method}

The "Rocking spalling" test, shortened in Rockspall, was developed by Forquin and co-authors [8-9] (Fig. 1) to investigate the crack velocity in concrete and rock-like materials under dynamic strain rates. It originated from the conventional spalling test [10-11]. The set-up consists from using a single Hopkinson bar along with a two-notch specimen put in contact with Hopkinson bar. The bigger notch creates a rocking effect on the rear free

Corresponding author: pascal.forquin@3sr-grenoble.fr 
part, which initiates the inception and the propagation of a crack from the smaller notch.

(a)
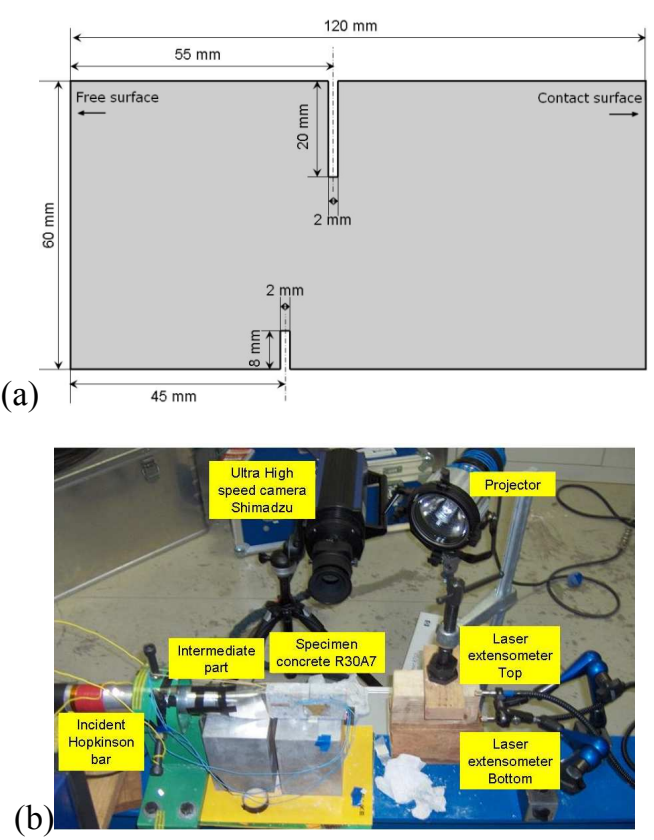

Fig. 1. Specimen geometry used in the rocking spalling tests and experimental set up used for dynamic crack propagation testing [8].

In this work, the tested sample is made of Hexoloy® ceramic material developed by Saint-Gobain. It is a high-performance ceramic used in armour systems. The sample is loaded by means of a Hopkinson bar made of steel. An example of sample geometry is shown in Fig. 2.

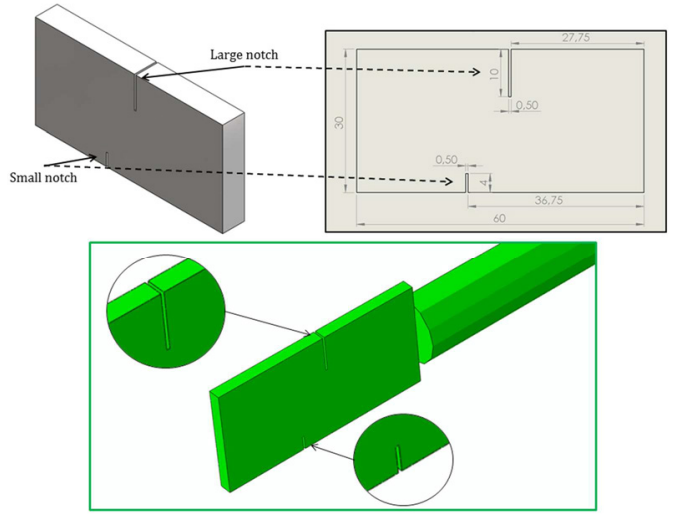

Fig. 2. Rockspall sample geometry (dimensions are in $\mathrm{mm}$ ) named 10-4-9 (large notch $=10 \mathrm{~mm}$, small notch $=4 \mathrm{~mm}$, distance between notches $=9 \mathrm{~mm}$ ) loaded with a Hopkinson bar $20 \mathrm{~mm}$ in diameter made of steel.

\section{Numericals simulationsn of Rockspall test}

\subsection{The DFH damage model}

The DFH (Denoual-Forquin-Hild) anisotropic damage model provides a description of the dynamic tensile behaviour of brittle materials at high strain-rates [2, 12].
This model is implemented in Abaqus $\backslash$ Explicit as a VUMAT subroutine. In the present work it is used to predict the velocity and propagation of one single crack in the form of a raw of damaged element. The damage variable $D$, is given for the current time $T$ according to the equations $[2,12]$ :

$$
D=P_{o}=1-e^{-\int_{0}^{T} \frac{\partial \lambda_{t}}{\partial t} V_{0}(T-t) d t}
$$

where $P_{o}$ is the probability of obscuration, $\lambda_{t}$ is the density of critical defects and $V_{0}(T-t)$ is given by:

$$
V_{0}(T-t)=S\left[k C_{0}(T-t)\right]^{n},
$$

where $k C_{0}$ corresponds to the crack velocity, $n=3$ is corresponds to the space dimension and $S$ is a shape parameter. The density of critical defects for a given stress $\sigma$ is given by:

$$
\lambda_{t}=\lambda_{0}\left(\frac{\sigma-\sigma_{u}}{\sigma_{0}}\right)^{m}
$$

there, $\sigma_{0}^{m} / \lambda_{0}$ is the Weibull scale parameter [13-14] computed knowing the Weibull modulus $m$, the effective volume $V_{\text {eff }}[15]$ and the mean tensile strength $\sigma_{w}$. The threshold stress $\sigma_{u}$ is set to zero. The DFH model was previously successfully used to simulate the fragmentation process in $\mathrm{SiC}$ ceramics [16-19].

\subsection{Mesh and model parameters}

The mechanical properties of the ceramic and steel used as Hopkinson bar are given in Table 1. The steel rod is meshed with C3D8R (8-node linear brick, reduced integration, hourglass control) $2-\mathrm{mm}$ in size and the ceramic is meshed with C3D8R elements of $0.5-\mathrm{mm}$. Symmetries are used to model only half of the total geometry. A stress pulse is applied at the opposite end of the bar (length $=0.5 \mathrm{~m}$ ) corresponding to the impact of a striker at $20 \mathrm{~m} / \mathrm{s}$.

\subsection{Numerical results}

A first step requires to determine the position of the second notch, which has to be placed where the axial tensile stress reaches the highest level to ensure the triggering and propagation of the crack (methodology shown in reference [8]). The small notch position being defined 3D numerical simulations were carried out with the DFH model. The simulation shows a crack represented by a raw of damaged elements starting to propagate between 130 and $131 \mu$ s.

At the end of the simulation, the crack is represented in Fig. 3d $(t=150 \mu \mathrm{s})$. The crack propagates through all the thickness of the specimen as shown in Fig. 4.

Several geometries of notches were considered in terms of size, and distance between the two notches. The denomination is the following: the first number is the length of the large notch, the second number is the length of the small notch, and the third number is the separation distance between both notches, in $\mathrm{mm}$. The different tested configurations are: 10-5-5, 8-4-9, 10-4-9, 
8-5-9, 8-4-5, 10-2-9, 8-3-9 so the influence of notch size and distance between notches was investigated.

Table 1. Material' properties used in numerical simulations.

\begin{tabular}{|l|c|}
\hline \multicolumn{2}{|c|}{ Ceramic properties } \\
\hline Density $\rho\left(\mathrm{kg} / \mathrm{m}^{3}\right)$ & 3180 \\
Young's modulus $E(\mathrm{GPa})$ & 410 \\
Poisson's coefficient $v$ & 0.14 \\
\hline Shape parameter $S$ & 3.74 \\
Constant $k$ & 0.38 \\
1D Wave speed $C_{0}(\mathrm{~m} / \mathrm{s})$ & 11355 \\
Effective volume $V_{\text {eff }}\left(\mathrm{mm}^{3}\right)$ & 7.5 \\
Weibull modulus $m$ & 9 \\
Mean tensile strength $\sigma_{w}(\mathrm{MPa})$ & 446 \\
\hline Steel properties & 7785 \\
\hline Density $\rho\left(\mathrm{kg} / \mathrm{m}^{3}\right)$ & 210 \\
Young's modulus $E(\mathrm{GPa})$ & 1.35 \\
Elastic limit $\sigma_{y}(\mathrm{GPa})$ & 0.3 \\
Poisson's coefficient $v$ & \\
\hline
\end{tabular}
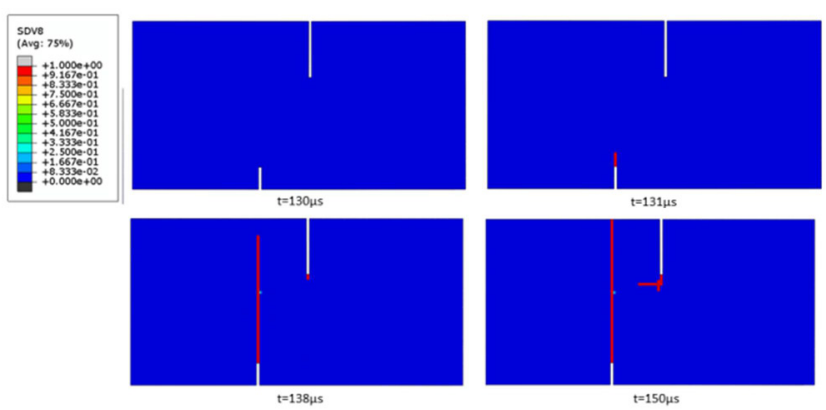

Fig. 3. Single crack propagation from small notch with 10-4-9 configuration, represented with the damage variable.
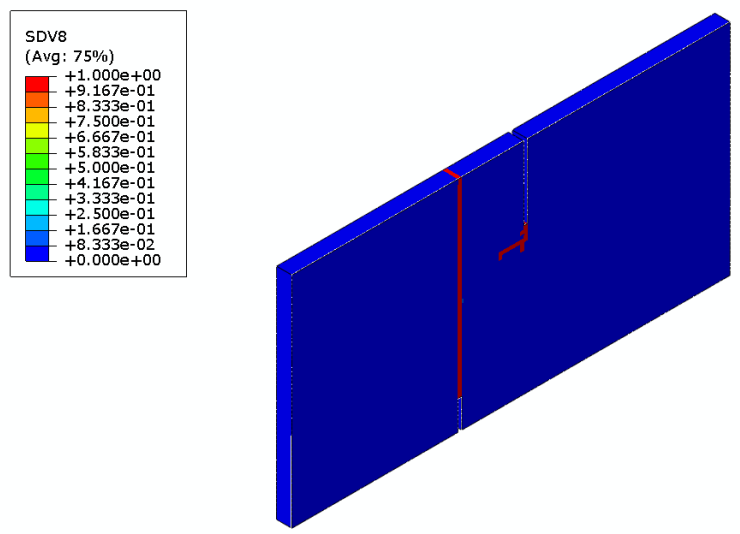

Fig. 4. Crack pattern at the end of the simulation $(t=150 \mu \mathrm{s})$, cut view $1.4 \mathrm{~mm}$ in-depth from the surface.

The position of the crack tip is plotted as function of time and the results are presented in Fig. 5. This figure stresses the ability of a single crack to initiate from the small notch and to propagate over a long distance. It is noted that the configurations 8-4-9 and 8-4-5 lead to a multiple fragmentation.

It can be seen that for the 10-4-9 configuration, the crack travels along all the width $(30-4=26 \mathrm{~mm})$, whereas in the 8-3-9 configuration the crack travels only over $11 \mathrm{~mm}$. When the size of the big notch is reduced $(8 \mathrm{~mm})$, the crack stops. This is likely due to the fact that the rocking effect is reduced. Owing to the fact that the big notch provides the dynamic tensile loading into the zone that contains the smaller notch, when the big notch is reduced, the size of the tensile loading zone is reduced as well and does not spread around the small notch. With a large notch of $10 \mathrm{~mm}$, the longer travel distance is observed with the configuration 10-4-9.

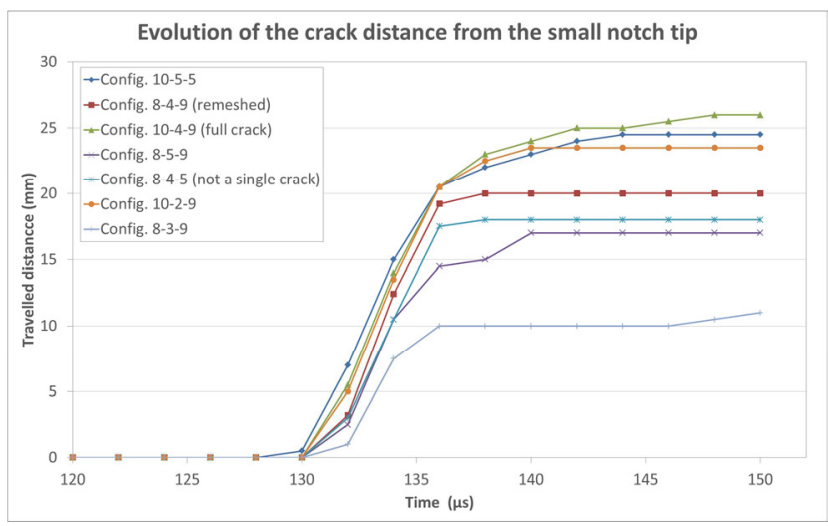

Fig. 5. Crack propagation as function of time in several Rockspall configurations.

Knowing the crack tip position, the velocity of the crack can be calculated by derivation of the distance over different increment of times, Fig. 6.

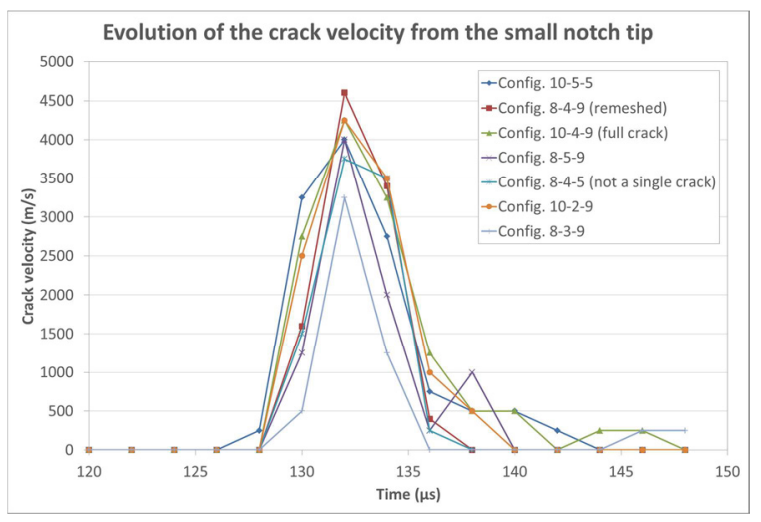

Fig. 6. Crack velocity calculated by time-derivation of the crack tip position.

The Rayleigh wave for the $\mathrm{SiC}$ being around $6739 \mathrm{~m} / \mathrm{s}$ it is possible to calculate the maximum crack velocity normalised by the Rayleigh wave speed. The minimum velocity is found at $3250 \mathrm{~m} / \mathrm{s}\left(0.48 C_{R}\right)$ in $8-3$ 9 testing configuration while it is $4600 \mathrm{~m} / \mathrm{s}\left(0.68 C_{R}\right)$ for 8-4-9 configuration.

\section{Conclusion}

An experimental configuration is proposed to study the dynamic crack propagation. The Rockspall test is based on a two-notch rectangular specimen, here made of a $\mathrm{SiC}$ ceramic (Hexoloy $\left.{ }^{\circledR}\right)$. The configuration 10-4-9 was found to be the best geometry for dynamic characterisation, since the DFH model predicts single crack propagation from the small notch along the whole width of the sample, considering an impact velocity of $20 \mathrm{~m} / \mathrm{s}$. The crack propagation estimated for the 10-4-9 
configuration is $4250 \mathrm{~m} / \mathrm{s}\left(0.63 C_{R}\right)$. This result will be compared with forthcoming experimental part.

The authors are grateful to the French division of the Ministry of the Armed Forces, that is the general direction of weaponry (DGA, Direction Générale de l'Armement) for sponsoring this work and to Saint-Gobain company for providing the tested ceramic samples.

\section{References}

1. M. A. Meyers, Dynamic behavior of materials, (John Wiley \& Sons, Inc., New York, 1994)

2. P. Forquin, F. Hild, A probabilistic damage model of the dynamic fragmentation process in brittle materials (Advances in Applied Mech. Giessen \& Are feds. 44, 1-72. Academic Press, San Diego, CA, 2010)

3. P. Forquin Brittle materials at high-loading rates: an open area of research. Phil. Trans. R. Soc. A (375) 20160436. DOI: 10.1098/rsta.2016.0436 (2017)

4. M.F. Kanninen, C.H. Popelar. Advanced fracture mechanics. Oxford (UK): Oxford University Press, 1985. 3. H. E. Edgerton and F. E. Barstow, Futher studies of glass fracture with high-speed photography, J. Am. Ceram. Soc., 24(4) 131-137 (1941)

5. D. Broek. Elementary engineering fracture mechanics. the Netherlands: Martinus Nijhoff, The Hague (1982)

6. E. Strassburger, H. Senf. Experimental investigations of wave and fracture phenomena in impacted ceramics and glasses, Ernst Mach Institute (1995)

7. K. Ravi-Chandar, W. G. Knauss. An experimental investigation into dynamic fracture: III. On steadystate crack propagation and crack branching, Int. J. Fract., 26(2), 141-154 (1984)

8. P. Forquin, An optical correlation technique for characaterizing the crack velocity in concrete, European Physical J. ST (2012)
9. P. Forquin and R. Cheriguène, A rocking spalling test to characterize the crack velocity in concrete, in Experimental and Applied Mechanics, Proulx T. (eds)., vol. 6, New York: Springer (2011)

10. J.R. Klepaczko, A. Brara. An experimental method for dynamic tensile testing of concrete by spalling. Int. J. Impact Eng. 25, 387-409 (2001)

11. B. Erzar, P. Forquin. An experimental method to determine the tensile strength of concrete at high rates of strain. Experimental Mechanics, 50(7), 941-955 (2010)

12. C. Denoual, F. Hild. A Damage Model for the Dynamic Fragmentation of Brittle Solids, Computer Methods in Applied Mechanics and Engineering, 247-258 (2000)

13. W. Weibull. A statistical theory of the strength of materials. Roy. Swed. Inst. Eng. Res, 151 (1939)

14. W. Weibull. A statistical distribution function of wide applicability. ASME J. Appl. Mech. 18, 293297 (1951)

15. D.G.S. Davies. The statistical approach to engineering design in ceramics. Proc. Brit. Ceram. Soc. 22, 429-452 (1973)

16. J. L. Zinszner, P. Forquin, and G. Rossiquet, Experimental and numerical analysis of the dynamic fragmentation in a $\mathrm{SiC}$ ceramic under impact, Int. J. Impact Eng., 76, 9-19 (2015)

17. J.-L. Zinszner, B. Erzar, P. Forquin, E. Buzaud. Dynamic fragmentation of an alumina ceramic subjected to shockless spalling: an experimental and numerical study. J. Mech. Phys. Solids, 85, 112-127 (2015)

18. J.-L. Zinszner., B. Erzar, P. Forquin. Strain-rate sensitivity of the tensile strength of two silicon carbides: experimental evidence and micromechanical modelling. Phil. Trans. R. Soc. A 20160167 (2017)

19. P. Forquin, E. Ando. Application of microtomography and image analysis to the quantification of fragmentation in ceramics after impact loading. Phil. Trans. R. Soc. A 20160166, (2017) 